\title{
A influência da interface na popularização do serviço de streaming de vídeo pirata Popcorn Time
}

\author{
The influence of the interface in the popularization of the pirate streaming video \\ service Popcorn Time \\ La influencia de lainterfazenlapopularizacióndelservicio de streaming de vídeo \\ pirata Popcorn Time \\ Liana Gross Furini ${ }^{1}$ \\ Roberto Tietzmann ${ }^{2}$ \\ http://dx.doi.org/10.5216/32260
}

\section{Resumo}

As discussões com relação à pirataria de produtos audiovisuais se tornaram mais intensas depois da popularização das tecnologias digitais, uma vez que elas colaboraram para a criação de um grande leque de possibilidades de circulação que vão além das formas oficiais de distribuição. Em contrapartida, a prática da pirataria através de tecnologias digitais exige uma quantidade de conhecimento técnico do interessado, o que acaba por ser uma barreira para grande parte dos usuários em adotar esta prática. Com uma interface simples, o serviço de streaming de material pirata Popcorn Time busca superar essa barreira técnica, reunindo elementos conhecidos de interface a um sistema de distribuição paralela.

Palavras-chave: Popcorn Time. Internet. Pirataria. Interface. Streaming.

\begin{abstract}
Discussions regarding the piracy of audiovisual products became more intense after the popularization of digital technologies, since they have collaborated to create a wide range of possibilities of circulation that go beyond the official forms of distribution. On the other hand, the practice of piracy through digital technologies requires some technical expertise, which turns out to be a barrier for most users' adoption of such practices. With a simple interface, the streaming service of pirated material Popcorn Time promises to overcome these limitations, combining known interface elements to the extraofficial distribution system.
\end{abstract}

Keywords: Popcorn Time. Internet. Piracy.Interface. Streaming.

\section{Resumen}

Lasdiscusiones sobre lapiratería de productosaudiovisuales se hizomás intensadespués de lapopularización de lastecnologíasdigitales, una vez que esascolaboran para crear una amplia gama de posibilidades para elmovimientoademás de las formas oficiales de distribución. Sin embargo, lapráctica de lapiratería através de tecnologíasdigitalesrequiere una serie de conocimientos técnicos, lo que resulta en una barrera para lamayoría de losusuarios a adoptar esta práctica. Con una interfazsencilla, el material de servicio de streaming pirata Popcorn Time busca superar esta barrera técnica, combinando elementos de interfazconocidos a un sistema de distribución paralela.

Palabras clave: Popcorn Time. Internet.Piratería. Interface. Streaming.

\footnotetext{
${ }^{1}$ Mestre pelo Programa de Pós-Graduação em Comunicação Social da Pontifícia Universidade Católica do Rio. Grande do Sul (PUCRS). Professora assistente na Pontifícia Universidade Católica do Rio Grande do Sul (PUCRS) e na Faculdades Integradas de Taquara (FACCAT). Brasil, Rio Grande do Sul, Porto Alegre. E-mail: lianagrossfurini@gmail.com

${ }^{2}$ Doutor pela Pontifícia Universidade Católica do Rio Grande do Sul (PUCRS). Mestre em Comunicação Social pela Pontifícia Universidade Católica do Rio Grande do Sul (PUCRS). Professor na Pontifícia Universidade Católica do Rio Grande do Sul (PUCRS), Faculdade de Comunicação Social (FAMECOS). Brasil, Rio Grande do Sul, Porto Alegre. E-mail: rtietz@pucrs.br
}

Comun. \& Inf., Goiânia, GO, v. 18, n. 1, p. 97-109, jan./jun. 2015 


\section{INTRODUÇÃO}

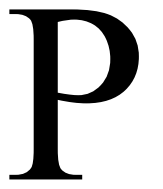

irataria se refere à apropriação não autorizada de produtos ou serviços que estejam sob resguardo de direitos autorais. Com relação a obras audiovisuais, a pirataria acompanha a indústria desde o começo da história do cinema, andando em paralelo às estratégias convencionais de distribuição. Apesar da luta da indústria audiovisual para tentar manter o controle sobre a distribuição do material, fica cada vez mais evidente que as janelas oficiais de distribuição de material cinematográfico não são os únicos espaços pelos quais os filmes circulam.

As tecnologias digitais colaboraram para que as pessoas pudessem assistir qualquer produção cinematográfica sem precisar sair das suas casas. "Em escala global, as tecnologias digitais estão possibilitando a ampliação da circulação, inclusive comercial, do produto cinematográfico em outros suportes" (BARONE, 2008, p. 06). Essas tecnologias contribuíram para a criação de uma nova forma de consumir esse tipo de mídia. "O uso doméstico e individual, os aparelhos de multimídia, a Internet, a popularização dos computadores são algumas das características destes novos tempos marcados pela variedade de equipamentos culturais" (SELONK, 2004, p. 162). A digitalização dos processos somada à difusão da internet apontada por Gilder (2001) e Castells (2008) facilitou a circulação das obras e fomentou um meio alternativo onde Gerbase (2007) destaca que "o espectador atua à margem do sistema e obtém o que quer baixando conteúdos disponíveis na rede, ou comprando uma cópia clandestina (...)” (p. 02).

A produção de cópias ilegais foi facilitada em função da popularização dos aparelhos digitais de reprodução e duplicação de material audiovisual. Diferente das fitas analógicas de áudio e vídeo, que perdem qualidade ao serem duplicadas, as tecnologias digitais permitem que os materiais digitais sejam copiados sem perder qualidade. "Por pouco ou nenhum custo, qualquer usuário de PC pode produzir milhares de cópias de software que pode ter levado anos de empenho e milhões de dólares para ser desenvolvido" ${ }^{3}$ (FLYNN, 2009, p. 143, tradução nossa). As tecnologias digitais e a internet, juntas, são grandes responsáveis para que pensemos que, a partir do momento que um produto de entretenimento foi criado, existem muitas chances de ser copiado.

A chegada das tecnologias digitais, assim como o aumento da transmissão e da capacidade de reprodução oferecido por essas tecnologias, fez com que os estúdios e

\footnotetext{
${ }^{3}$ Do original, "For little or no cost, any PC user can produce thousands of copies of software of software that may have taken years to effort and millions of dollars to develop".
}

Comun. \& Inf., Goiânia, GO, v. 18, n. 1, p. 97-109, jan./jun. 2015 
distribuidoras perdessem parte do controle sobre a distribuição de seus filmes. A facilidade de replicação e transmissão presente na internet a situa como um espaço de disputa: ao mesmo tempo se coloca como um repositório infinito de atrações e pode ser apontada como um espaço de prática de atividades ilícitas favorecida pela tecnologia. $\mathrm{Na}$ linha de frente desta disputa está o que é definido amplamente como pirataria.

A internet, em sua essência, tende a eliminar a necessidade de um intermediário (WILSON, 2014), e prova disso é o sucesso das formas P2P (peer-to-peer) de compartilhamento de conteúdo e dos sites de lojas virtuais que podem ser criados por qualquer usuário. Para Bergan (2006), a internet é o maior desafio da indústria cinematográfica atual. As exibições online e, principalmente, os downloads, alimentam receios de que a pirataria se torne generalizada e a produção cinematográfica entre em crise. A "rede mundial de computadores" promete ser um catálogo interminável de filmes, com público infinito e com custo extremamente baixo.

As tecnologias digitais e a internet trouxeram muitas novas possibilidades de compartilhamento de arquivo. Um exemplo é a melhora na qualidade dos streamings ao vivo, o que fez com que esse tipo de exibição fosse, muitas vezes, mais atraente para o público (NETRESULT, 2011) do que o download, por exigir menos experiência do usuário e também por não exigir que o usuário mantenha um arquivo no seu computador. Para baixar um filme através da tecnologia torrent, por exemplo, o usuário precisa acessar o site em que o arquivo está disponível, fazer o download e transferir o arquivo para o seu computador através de um software, denominado cliente.Isso exige uma experiência do usuário e, por isso, exclui da prática aqueles internautas que tem menos conhecimento. Nesse sentido, trazemos para a discussão o lançamento de serviços de streaming de vídeo piratas, que transmitem materiais audiovisuais protegidos por direitos autorais e permitem, através de interfaces simples, que usuários menos experientes possam acessar o material. Como os filmes são transmitidos por streaming, o usuário precisa apenas clicar no play, excluindo a dificuldade imposta pelo download de torrent.

\section{OS SERVIÇOS DE STREAMING DE MATERIAL AUDIOVISUAL E O POPCORN TIME}

As cópias não autorizadas se tornaram uma questão presente no cotidiano dos usuários comuns a partir da consolidação do vídeo doméstico com a bitola VHS, primeiro suporte de vídeo usado para a revenda de filmes a partir de 1977 conforme Wasser (2001). A

Comun. \& Inf., Goiânia, GO, v. 18, n. 1, p. 97-109, jan./jun. 2015 
possibilidade de gravar programas da televisão e duplicar em grande escala filmes prégravados semeou a noção de que estas cópias não seriam pirataria - uma palavra investida de conotações negativas e jurídicas - mas uma possibilidade de diálogo e trocas domésticas e não-comerciais entre indivíduos, grupos e fãs. Essencialmente, estas práticas de duplicação analógica poderiam ser entendidas como um direito de uso, movimento que foi encarado como perda de receitas pelas empresas do ramo. Esse debate só aumentou com a difusão dos computadores pessoais na década de 1980 que, a partir da década seguinte, passaram a ter sua capacidade de armazenamento e de processamento de conteúdos multimídia constantemente melhorados. Para completar o cenário, a penetração de internet em banda larga, ao longo da primeira década do século XXI, criou condições para a aceitação de plataformas de vídeo online.

Atualmente, no Brasil, são mais de oitenta milhões de internautas (AGUIARI, 2012), um número que cresceu 1.484,9\% de 2000 a $2011^{4}$. Estes usuários, conforme Aguiari (2012), em sua maioria (45\%), têm acesso a rede em velocidades que variam de $512 \mathrm{Kbps}$ até 2 Mbps, seguidos por 2 a 8 Mbps (27\% dos usuários), um limiar de velocidade que pode não oferecer a experiência para consumo de vídeo online que tornaria esses usuários capazes de substituir a televisão por completo, mas que dá a eles acesso a um vasto universo de produtos audiovisuais online. Esses dados nos mostram que a circulação de material por meios paralelos, mesmo que não substitua completamente a circulação por meios tradicionais, levantam a possibilidade de muitas pessoas terem acesso a essas obras por meios que vão além das formas oficiais de distribuição.

A internet possibilitou o aumento desse leque de exibição oficial, com canais de aluguel de filme como Blockbuster ${ }^{5}$, Netflix ${ }^{6}$, Sunday $\mathrm{TV}^{7}$, Globo TV ${ }^{8}{ }^{8}$ Mubi $^{9}$, IndieFlix ${ }^{10}$, Vodo $^{11}$ e canais de exibição de vídeos, como o Vimeo ${ }^{12}$ e o YouTube ${ }^{13}$. Além desses serviços, que são bastante conhecidos, a MPAA fez uma lista ${ }^{14}$ de 100 serviços online para assistir filmes de forma legal. Esses canais, segundo Foxton (2014), são uma forma de a indústria

\footnotetext{
${ }^{4}$ Segundo informações do site Internet World Stats. Disponível em: $<$ http://www.internetworldstats.com/stats15.htm\#south>. Acesso em 08 de ago. 2014.

${ }^{5}$ Disponível em $<\mathrm{http}: / /$ www.blockbuster.com/>. Acesso em: 03 de abr. 2014.

${ }^{6}$ Disponível em $<\mathrm{http}: / /$ www.netflix.com/>. Acesso em: 03 de abr. 2014.

${ }^{7}$ Disponível em $<\mathrm{http}: / /$ sundaytv.terra.com.br/Web/>. Acesso: em 03 de abr. 2014.

${ }^{8}$ Disponível em $<\mathrm{http}: / /$ globotv.globo.com/mais/>. Acesso em: 03 de abr. 2014.

${ }^{9}$ Disponível em $<$ https://mubi.com/>. Acesso em: 11 de ago. 2014.

${ }^{10}$ Disponível em $<$ https://indieflix.com/>.Acesso em: 11 de ago. 2014.

${ }^{11}$ Disponível em $<$ https://vodo.net/films/>. Acesso em: 11 de ago. 2014.

${ }^{12}$ Disponível em $<\mathrm{http}: / /$ www.vimeo.com/>. Acesso em: 03 de abr. 2014.

${ }^{13}$ Disponível em $<$ http://www.youtube.com/>. Acesso em: 03 de abr. 2014.

${ }^{14}$ Disponível em $<$ http://www.mpaa.org/looking-to-watch-a-movie-or-tv-show-there-are-now-100-legitimateonline-services-in-the-u-s/\#.U3_dcFhdVQo>. Acessoem: 11 de agosto de 2014.
}

Comun. \& Inf., Goiânia, GO, v. 18, n. 1, p. 97-109, jan./jun. 2015 
seguir ganhando dinheiro com filmes antigos, que não estão mais disponíveis para serem vistos no cinema - e que vem perdendo espaço com os registros de quedas nas vendas de DVD. Serviços como esses são "uma forma de fazer dinheiro com o catálogo antigo e combater a pirataria ao mesmo tempo"15 (FOXTON, 2014, online, tradução nossa).

Netflix é um serviço particularmente interessante. Criado em 1997 com a proposta de oferecer aluguel de filmes online, não parou de crescer desde então. O modelo de negócio da Netflix se adapta muito bem à nova forma de consumir mídia que o público internauta demanda. Os assinantes podem assistir online o conteúdo através de um software de transmissão usando sua televisão, notebook ou dispositivo mobile que ofereça o aplicativo da Netflix. Segundo o site oficial ${ }^{16}$, a empresa já conta com mais de 40 milhões de assinantes em mais de 40 países e é, por consequência, o principal serviço de TV por internet do mundo. Os assinantes assistem a mais de um bilhão de horas de conteúdo original por mês. Atualmente, a Netflix é responsável por quase um terço de todo o tráfego doméstico de internet nos Estados Unidos (VANCE, 2013).

Além desses canais, que complementam a comercialização dos filmes, existem também muitos outros que ampliam a circulação dessas obras, todavia, de forma não oficial. Dentre estes, podemos citar a venda de videocassete, DVD e Blu-Ray piratas, download através de sites de torrent, sites de download direto ou blogs que fazem curadoria desses conteúdos e sites de visualização de vídeos.

Grande parte do material obtido de forma não-oficial na internet chega ao consumidor através do protocolo torrent. Essa tecnologia facilita o acesso a arquivos pesados (como um longa-metragem, por exemplo), mas atende apenas os mais heavy users, em função de depender de um conhecimento técnico que grande parte dos usuários não têm. Nesse sentido, os serviços de streaming facilitam a vida dos usuários com menor conhecimento técnico em função de ter uma interface simples. Esses serviços, então, são facilitadores do consumo através de meios paralelos aos oficiais, conceito que vai ser mais explorado no tópico a seguir.

A possibilidade de assistir a materiais disponíveis através da tecnologia de torrent sem a necessidade de fazer o download prévio do arquivo, acelerando, assim, o seu consumo aparece, então, como uma proposta inovadora. Desse conceito surgiu, em março de 2013, o Popcorn Time ${ }^{17}$, serviço de streaming criado por argentinos, apelidado de Netflix da pirataria.

\footnotetext{
${ }^{15}$ Do original, "a way to make cash out of the back catalogue, and beat piracy at the same time".

${ }^{16}$ Disponível em: <http://www.netflix.com/>. Acesso em: 20 de mar. 2014.

${ }^{17}$ Disponível em: <http://getpopcornti.me/>. Acessoem: 20 de mar. 2014.
}

Comun. \& Inf., Goiânia, GO, v. 18, n. 1, p. 97-109, jan./jun. 2015 
O serviço disponibilizava os filmes por streaming e, dessa forma, o usuário não precisava manter uma cópia do material em seu computador, característica importante porque, dessa forma, o usuário não precisaria manter uma prova do crime. Temendo um posicionamento contrário por parte da indústria audiovisual (que, nas palavras deles, é antiga e faz de tudo para ganhar dinheiro), os criadores do Popcorn Time tiraram o serviço do ar, deixando na capa do site uma mensagem explicando o motivo. Nesse texto, os criadores dizem que o que eles chamaram de experimento colocou-os "à porta de infinitos debates sobre pirataria e direito autoral, questões legais e o sistema obscuro nos fez sentir em perigo por fazer o que amamos. E essa não é uma batalha da qual queremos participar" ${ }^{18}$ (POPCORN TIME, 2014, online, tradução nossa).

Esse seria o fim do serviço se não fosse por um motivo: ele tinha seu código aberto. Isso possibilitou que, rapidamente, outros criadores fizessem suas versões do Popcorn Time. "Bastou um final de semana para que o serviço voltasse a funcionar. Outras pessoas, que compartilhavam do ideal dos criadores, e estavam dispostas a correr os riscos e esforços para manter o serviço no ar, já o reviveram" (BERNARDO, 2014, tradução nossa). O serviço foi adotado pelo grupo YTS (ou YIFY, como são conhecidos no meio das legendas) e segue no $\operatorname{ar}^{19}$ (ANDY, 2014).

Uma publicação no site Business Insider ${ }^{20}$ afirma que o pesadelo de Hollywood está apenas começando (FOXTON, 2014). Foxton aponta a facilidade de uso do Popcorn Time como o seu grande diferencial. "Não exige nenhuma habilidade de tecnologia, não te força a navegar por um monte de anúncios imprestáveis e não demora horas para funcionar; é só apontar e clicar" ${ }^{21}$ (FOXTON, 2014, online, tradução nossa). Para o autor, a facilidade do uso é um fator muito importante e que muitas vezes passa despercebido. Ele afirma que muitas pessoas deixam de baixar conteúdo ilegalmente em função de que os bloqueios de sites como The PirateBayestão cada vez mais difíceis de quebrar. Essa situação é reforçada com lançamentos de canais oficiais de streaming de vídeos na internet, como o Netflix, que tem um funcionamento mais fácil do que os downloads. Outra grande vantagem do Popcorn Time em relação a outros serviços de streaming, principalmente os oficiais, é o catálogo. Serviços como o Netflix não teriam como manter um vasto catálogo de filmes em função do preço a

\footnotetext{
${ }^{18}$ Do original, "Our experiment has put us at the doors of endless debates about piracy and copyright, legal threats and the shady machinery that makes us feel in danger for doing what we love. And that's not a battle we want a place in".

${ }^{19}$ Seu endereço foi alterado para https://github.com/yify.Acesso em 20 de março de 2014.

${ }^{20}$ Disponível em http://www.businessinsider.com/. Acesso em: 29 de agosto de 2014.

${ }^{21}$ Do original, "doesn't require any tech skills, it doesn't force you to navigate a ton of scummy ads and it doesn't take hours to work; it's just point and click".
}

Comun. \& Inf., Goiânia, GO, v. 18, n. 1, p. 97-109, jan./jun. 2015 
ser pago para as produtoras e distribuidoras (FOXTON, 2014). Já com relação a serviços piratas, esse não é um problema, visto que eles disponibilizam para o seu cliente um vasto catálogo, recheado de lançamentos e blockbusters, sem pagar por isso.

\section{POPCORN TIME E SUA INTERFACE COMO FACILITADORES DO CONSUMO}

Uma das questões determinantes na adoção de tecnologia e seus dispositivos pela maioria dos consumidores está relacionada com a facilidade de uso envolvida neste processo. A percepção da complexidade envolvida para atingir a gratificação buscada com a tecnologia está relacionada com aspectos de usabilidade dos produtos como afirmam Laurel (1990), Nielsen (1995) e Norman (1988) e em um sentido mais amplo com a busca de uma mediação entre indivíduo e máquina pautada por princípios ergonômicos como exploram Karwowski (2006) e Salvendy (2012). Estas relações acontecem em paralelo com a mera avaliação de custo e benefício na adoção de tecnologias, estando vinculadas ao quão fácil ou proveitoso será seu uso aos usuários.

A quantidade de passos necessária para assistir a um filme de longa metragem copiado extraoficialmente da internet envolve tanto a aquisição de hardware dedicado a este fim (um computador pessoal), contratos com serviços por assinatura (um provedor de banda larga) e um repertório de informações a respeito de onde encontrar as obras desejadas, como descarregá-las, como diferenciar qualidades e versões publicadas sob nomes falsos, além de como adaptá-las à língua desejada, o que complica o consumo enquanto acena com uma promessa de abundância de conteúdos.

A complexidade envolvida e as incertezas do processo são maiores do que assistir ao mesmo filme em um disco de DVD, o que abre o caminho para as cópias extraoficiais distribuídas por camelôs em pontos de grande movimento das cidades e também a busca de estratégias para tornar o uso destes conteúdos audiovisuais mais simplificado, uma problematização onde se insere o aplicativo Popcorn Time.

A aparência da interface dos serviços de streaming de filmes na internet - a exemplo doPopcorn Time -semelhante a uma prateleira de filmes, é uma solução presente também em outros serviços de oferta de vídeo online, entre eles seu contraparte na distribuição oficial, Netflix. Nesta seção do texto, problematizamos a genealogia desta interface que traz em sua forma um somatório de soluções e metáforas agregadas ao longo do tempo como uma solução adequada para a representação dos conteúdos audiovisuais e as ações sobre eles propostas pelo software. 


\section{CONCEITUANDO INTERFACES E METÁFORAS}

Uma interface é algo que liga dois ou mais pontos distintos entre si, estabelecendo a possibilidade de comunicação e trocas entre eles. Conforme Laurel (1990) uma interface é uma superfície porosa de contato que reflete assim as propriedades físicas e técnicas de cada participante do processo bem como as funções a serem executadas e o equilíbrio de poder e controle envolvido. Ao fazer contato entre dois ambientes, tem conhecimento das propriedades, qualidades e idiossincrasias dos dois pontos e inclusive de sua materialidade ou não, o que abre caminho para o uso de interfaces como dispositivos capazes de potencializar a manipulação e consumo de conjuntos de informação como nos computadores e redes digitais contemporâneas.

O design de uma interface estabelece uma forma de entender com os sentidos o que é abstrato, viabilizar a tomada de decisões a respeito do que é apresentado e transformar pensamentos em ações no espaço virtual de informação dotado de consistência, mas não de materialidade. Como afirma Mok (1996) uma interface tem a obrigação básica de fornecer uma sugestão para ações específicas, facilitando o contato entre os meios digitais e seus usuários.

Um caminho recorrente para isto tem sido o uso de metáforas visuais e funcionais na construção das interfaces humano-computador. Metáforas visuais nesta área foram introduzidas ao grande público a partir da apresentação do primeiro computador Macintosh em 1984, aproximadamente uma década após de serem experimentalmente desenvolvidas pela Xerox em seus laboratórios de pesquisa onde encontraram pouca repercussão comercial como relatam Ceruzzi (2003) e Levy (1994).

Segundo Ehses (1988), foi Umberto Eco quem primeiro sugeriu a aplicação de figuras de linguagem (tradicionalmente aplicadas à expressão oral e escrita) na comunicação visual. Ainda que Eco não estivesse considerando as interfaces nesta afirmação, ela vai de encontro ao que Negroponte (1995) relata em suas crônicas a respeito a busca de uma facilidade de uso como chave para a massificação dos computadores e dispositivos digitais. Ehses eLupton (1988) afirmam que uma figura de linguagem é um desdobramento a partir do uso ordinário da linguagem e definem uma metáfora como uma "comparação implicada entre dois objetos sem nada em comum que têm alguma similaridade estrutural" (p.18), o que pode ser entendido como uma relação de semelhança de forma e função entre o que é visto na tela e 
o que se conhece do mundo exterior a ela. A ideia do uso de metáforas visuais é referendada nos guias de planejamento da Apple Computer (1992a, 1992b, 1992c, 1993), que afirmam:

Você pode tirar proveito do conhecimento que as pessoas têm do mundo à sua volta usando metáforas para traduzir conceitos e características de seu programa. Use metáforas envolvendo ideias concretas e familiares e faça as metáforas simples, de maneira que os usuários tenham um conjunto de expectativas a aplicar a ambientes gerados em computador (Apple, 1992b, p. 04).

É importante observar que, para facilitar a compreensão da metáfora, o ponto de onde ela parte precisa ser conhecido e compartilhado pelo seu criador e por quem entra em contato com ela. Aproximando esta noção da interface do Popcorn Time que problematizamos neste artigo, a ideia de uma prateleira de filmes tem de guardar alguma semelhança com uma prateleira real, mesmo que não esteja restrita pelos limites físicos que uma prateleira material imporia à manipulação das imagens. A metáfora, portanto, opera como um facilitador para a compreensão das regras constantes presentes na tela e em seus conteúdos através das comparações que propõe.

\section{UMA GENEALOGIA DA INTERFACE DE PRATELEIRA USADA EM POPCORN TIME}

Ao questionarmos a presença da metáfora de prateleira no aplicativo Popcorn Time se faz necessário investigarmos possíveis origens desta solução. Ainda que a justificativa mais imediata esteja na busca de semelhança com um modelo de usabilidade e ergonomia consagrado na distribuição de vídeo online encontrado na Netflix, sustentamos que esta solução reflete implicações mais profundas da indústria produtora de audiovisual, respondendo a uma problemática anterior de como mudar a visualização de um conteúdo audiovisual em um suporte estático.

A partir de Gaudreaultet al (2012) e King (2003) podemos afirmar que a indústria do cinema e do audiovisual sempre negociou com uma ambiguidade intrínseca ao seu negócio: embora seus produtos sejam baseados em imagens em movimento, seus anúncios em várias formas de divulgação eram feitas em meios que não eram capazes representar o movimento pleno, como cartazes, folhetos e demais anúncios impressos ou seus correspondentes digitais.

Isto deu origem à necessidade traduzir a experiência do movimento e das narrativas através uma série de convenções visuais que continuam a ser repetidas e relidas em pôsteres século 21 adiante. Entre o repertório de situações conhecidas e repetidas nos pôsteres se incluem: uma colagem de fragmentos de cenas do filme; o destaque a um personagem

Comun. \& Inf., Goiânia, GO, v. 18, n. 1, p. 97-109, jan./jun. 2015 
protagonista; uma cena-chave da narrativa é apresentada em um enquadramento adaptado ao formato vertical da peça; uma ilustração redesenha temas, cenas ou personagens do filme, etc. Todas estas soluções operam como sinédoques do filme - a figura de linguagem onde a parte representa o todo - invariavelmente estabelecendo um contrato de compra e venda entre realizador e espectador onde os elementos apresentados no pôster serão entregues à plateia assim que começar a sessão.

A própria arquitetura e ergonomia das salas de cinema ajudou a definir o tamanho de um pôster: grande o suficiente para ser visto à distância ou coletivamente, ainda portátil de maneira que fosse possível ser transportado junto com as cópias do filme à medida que circulavam entre as cidades. O caráter segmentado da indústria entre produtores, distribuidores e exibidores fazia com que a escolha do que seria exibido em cada sala de cinema já estava em boa parte determinado antes de alcançar suas plateias, diminuindo a necessidade para cartazes serem apresentados juntos, exceto quando eram usados para chamar atrações que estavam porvir.

A primeira aproximação a algo semelhante à interface presente na Netflix ou no Popcorn Time aparece em anúncios de jornal dos filmes em exibição nos cinemas ao longo do século XX. Ao tentar despertar a atenção dos consumidores que desejavam escolher qual filme assistir em meio à lista eram comuns as reduções e edições simplificadas das artes dos pôsteres nos pequenos anúncios, limitadas pelas soluções de impressão disponíveis no periódico. O que isto mostra é que assim que começa a haver uma necessidade de negociar a apresentação de uma grande quantidade de opções, algum tipo de organização espacial ou informacional se fará presente, sugerindo caminhos para que as demandas qualifiquem a busca entre os dados como informação com o mínimo de esforço que o meio permite.

A interface de prateleira tem a raiz de sua metáfora justamente nos serviços e empresas que tanto o Netflixou o Popcorn Time vieram a substituir: as videolocadoras. Ao longo das décadas de 1980 e 1990 o consumo de audiovisual se afastou de estar vinculado às transmissões de televisão ou às salas de cinema de maneira exclusiva a partir da difusão dos formatos de vídeo doméstico e sua exploração como um canal de veiculação de filmes prégravados.

A abundância de títulos, a arte de capa das caixinhas que se apropriava da arte dos pôsteres, a brevidade do espaço da maioria destas lojas e a organização preferencialmente por gênero de filme são elementos que migraram para a interface da maioria dos serviços de vídeo online. Mais uma vez, podemos observar que este movimento está relacionado com o próprio 
conceito de criação de uma interface baseada em metáforas em que parte de algo conhecido para dar forma a algo desconhecido, reassegurando, assim, que os consumidores poderão adotar a novidade tecnológica com o mínimo de problemas de adaptação possível, algo desejado tanto pelos serviços comerciais oficiais quanto pelos extraoficiais de distribuição de conteúdo.

\section{CONSIDERAÇÕES FINAIS}

As tecnologias digitais e a internet trouxeram novas possibilidades de compartilhamento de arquivos, além de permitir que o usuário final tenha parte do controle sobre a circulação dos materiais, à revelia da autorização das produtoras e distribuidoras. Esse fenômeno contribuiu para o aumento da discussão com relação à pirataria digital.

Mesmo que tenha sido facilitada em função da popularização das tecnologias digitais, a pirataria digital exige do usuário um conhecimento de ferramentas e de suas convenções e etiqueta códigos sociais. Isso afasta aquele usuário que não é familiar às convenções da tecnologia. Isso é ainda mais expressivo quando se trata de pirataria através da tecnologia torrent, porque o usuário, além de dominar o funcionamento dos sites que disponibilizam esse tipo de arquivo, necessita de um programa (que deve ser instalado no seu computador) para conseguir fazer o download do arquivo. Assim, o serviço Popcorn Time operar com streaming escondendo sua infraestrutura tecnológica de protocolo torrent pode ser o suficiente para atrair esse usuário com menor conhecimento técnico. $\mathrm{O}$ usuário que assiste filmes através do Popcorn Time tem acesso a uma interface calcada em uma metáfora bastante simples e conhecida de outros meios inclusive exteriores à tela, o que pode aproximá-lo destas práticas, mas cuja aparência da interface não garante a confiabilidade e a estabilidade alcançada por serviços comerciais.

\section{REFERÊNCIAS}

AGUIARI, V. PNBL e 3G fazem número de brasileiros online chegar a 79,9 milhões. Revista Info. Editora Abril, São Paulo, 10 abr. 2012. Disponível em

$<$ http://info.abril.com.br/noticias/internet/brasil-fecha-2011-com-79-9-mi-de-internautas-1004201229.shl>. Acessoem: 11 de jul. 2014.

ANDY. Popcorn Time shuts down, then gets resurrected by YTS (YIFI). TorrentFreak, 2014. Disponível em: $<$ https://torrentfreak.com/popcorn-time-shuts-down-then-gets-resurrected-by-yts-yify140315/>.Acessoem: 20 de mar. 2014.

APPLE COMPUTER INC. Apple CD-ROM handbook: a guide to planning, creating, and producing a CD-ROM. [S.1.]: Addison Wesley, 1992. 
APPLE COMPUTER INC. Macintosh Human Interface Guidelines. [S.1.]: Addison Wesley,1992.

BARONE, J. G. Exibição, crise de público e outras questões do cinema brasileiro. Revista Sessões do Imaginário. Porto Alegre, ano 13, n. 20, 2008.

BERGAN, R. Cinema. Rio de Janeiro: Jorge Hazar Editor, 2006.

BERNARDO, K. Popcorn Time e o poder do código aberto. Startupi, [S.1.], 2014. Disponível em: $<$ http://startups.ig.com.br/2014/popcorn-time-e-o-poder-codigo-aberto/>.Acesso em: 20 de março de 2014.

CASTELLS, M. A era da informação: economia, sociedade e cultura. 11. ed. São Paulo: Paz e Terra, 2008.

CERUZZI, P. E. A Historyofmoderncomputing. 2. ed. United States of America: MIT Press, 2003.

EHSES, H.; LUPTON, E. Design papers: rhetorical handbook. Nova Scotia, CA: Halifax: Design Division, College of Art and Design, 1988. (Design Papers 5.)

FLYNN, N. E-Policy handbook: rules and best practices to safely manage your company's e-mail, blogs, social networking, and other electronic communication tools. 2.ed. Saranac Lake: Amacom Books, 2009.

FOXTON, W. Popcorn Time: hollywood's nightmare is only just beginning. Business Insider, [S. 1.]. Disponível em: <http://www.businessinsider.com/popcorn-time-is-hollywoods-nightmare-20143\#ixzz3BoCILBD8>.Acessoem: 29 de ago. 2014.

GAUDREAUlT, A.; DULAC, N.; HIDALGO, S. A companion to early cinema. Chichester: John Wiley \& Sons, 2012.

GERBASE, C. Enxugando gelo: pirataria e direitos autorais de obras audiovisuais na era das redes. ECompós. v. 10, 2007.

GILDER, G. Telecosmo: a era pós computador. São Paulo: Campus, 2001.

KARKWOWSKI, W. International encyclopedia of ergonomics and human factors. 2. ed. Boca Raton: CRC Press, 2006. v. 4.

KING, E. A century of movie posters: from silent to art house. New York: Barron's, 2003.

LAUREL, B. Art of human-computer interface design. Reading: Addison Wesley, 1990.

LEVY, S. Insanely great: the life and times of macintosh, the computer that changed everything.Nova Iorque: Penguin Books, 1994.

POPCORN TIME. Disponível em:<http://getpopcornti.me/>.Acesso em: 20 de mar. 2014.

MOK, C.Designing business. Nova Iorque: Adobe Press, 1996.

NEGROPONTE, N. A vida digital. São Paulo: Companhia das Letras, 1995.

NETRESULT. Update on digital piracy of sporting events 2011: submitted in call for evidence to independent review of intellectual property and growth. London: NetResult, 2011. Disponível em $<$ www.wipo.int/export/sites/www/ip-sport/en/pdf/piracy_report_2011.pdf $>$. Acessoem: 31 de jul.2014.

Comun. \& Inf., Goiânia, GO, v. 18, n. 1, p. 97-109, jan./jun. 2015 
NIELSEN, J. Usability engeneering. Chestnut Hill: AP Professional, 1995.

NORMAN, D. The design of everyday things. Nova Iorque: Currency Doubleday, 1988.

SALVENDY, G. Handbook of human factors and ergonomics. Canadá: FourthEdition, 2012.

SELONK, A. P. de A.Distribuição cinematográfica no brasil e suas repercussões políticas e sociais: um estudo comparado da distribuição cinematográfica nacional e estrangeira. 2004. 198 f.Dissertação (Mestrado em Comunicação Social) - Faculdade de Comunicação Social, Pontifícia Universidade Católica do Rio Grande do Sul, Porto Alegre, 2004.

VANCE, A. Netflix, reed hastingssurvive missteps to Join Silicon Valley's Elite. Business Week, [S. 1.], 2013. Disponívelem:<http://www.businessweek.com/articles/2013-05-09/netflix-reed-hastingssurvive-missteps-to-join-silicon-valleys-elite>. Acessoem: 11 de nov.2013.

WASSER, F. Veni, vidi, video: the hollywood empire and the VCR. Austin: Texas film and media studies series, 2001.

WILSON, F. Platform Monopolies. Business Insider, jul.2014. Disponível em: $<$ www.businessinsider.com/platform-monopolies-2014-

7?utm_content=bufferf6f $44 \& u t m \_$medium $=$social\&utm_source=twitter.com\&utm_campaign=buffer $>$ . Acesso em: 12 de ago. 2014.

Recebido em: $14 / 10 / 2014$

Aceito em:16/11/2014

Publicado em: 15/06/2015 